\title{
Deductive reasoning and learning
}

Mariusz Urbański, Katarzyna Paluszkiewicz, Joanna Urbańska

\{Mariusz.Urbanski, Katarzyna.Paluszkiewicz, Joanna.Urbanska\}@amu.edu.pl

ADAM MICKIEWICZ

UNIVERSITY

IN POZNAŃ

Institute of Psychology, Adam Mickiewicz University, Poznań, Poland

\section{Problems}

1. What, if any, is a correlation between fluid intelligence (Gf) and fluencies in both 'easy' and 'difficult' deductions?

2. What, if any, is the impact of learning on the level of Gf and fluencies in both kinds of deductions?

As examples of easy deductions we employed simple syllogistic reasoning in abstract settings. Difficult deductions were exemplified by complex conditional inferences in the form of erotetic reasoning (which involves questions as conclusions).

\section{Tools}

Raven's Advanced Progressive Matrices (APM; $\alpha=.83$

Deductive Reasoning Test (DR; $\alpha=.64)$. The test contains 6 items (time limit $20 \mathrm{~min}$ ). Each item consists of two declarative premises and a question concerning which conclusion is justified by the premises. Three items are of categorical character and three of relational character, all set in abstract context.

Erotetic Reasoning Test (ER; $\alpha=.78)$. The test contains 3 items (time limit $30 \mathrm{~min}$ ). Each item consists of a detective-like story in which the initial problem and evidence gained are indicated. The task is to pick a question (one out of four), each answer to which will lead to some solution to the initial problem. The subjects are asked to justify their choices.

Both reasoning tests were designed by the authors and were carried out in Polish.

\section{Subjects}

105 subjects were recruited $(\mathrm{M}=21.69, \mathrm{SD}=1.44,88$ women), students who volunteered to participate in this research. They represented the curricula of cognitive science, psychology, educational studies (2nd, 4th or 5 th year). The choice of the curricula was determined by three factors: (i) scientific area affiliation, (ii) the extent of logic courses, and (iii) selectivity of admission procedures, based on A-level examination results. We distinguished three groups:

A extensive logic, selective admission (cognitive science; 27);

B basic logic, selective admission (psychology; 40);

$\mathrm{C}$ basic logic, non-selective admission (educational studies; 38).

(Apparently, there is no social science curriculum of 'extensive logic, non-selective admission'-type in Poland.) None of participants received any extra-curricular training in logic. Participants from groups A and B received, as a part of their curricula, a training in statistics (the same in case of both groups). Participants from group A received also some training in programming languages.

To each participant we administered three test in one 90 minute session (in groups of ca. 20 persons).

\section{References}

[1] Belsky, J. K. [1990]. The psychology of aging theory, research, and interventions. Pacific Grove, CA: Brooks/Cole.

2] Cattell, R. B. [1971]. Abilities: Their structure, growth, and action. New York: Houghton Mifflin.

[3] Jaeggi, S. M., Buschkuehl, M., Jonides, J., Perrig, W. J. [2008]. Improving fluid intelligence with training on working [2008]. Improving fluid intelligence with training on working
memory. PNAS - Proceedings of the National Academy of

[4] Kline, P. [1998]. The new psychometrics: Science, psychology and measurement. London: Routledge.

[5] Raven, J. C., Court, J. H., Raven J. [1983]. Manual for Raven, J. C., Court, J. H., Raven J. [1983]. Manual for Raven's Progressive Matrices and vocabulary scales (Section

Stenning, K, van Lambalgen, M. [2008]. Human Reasoning. Stenning, K., van Lambalgen, M.
Cambridge, MA: The MIT Press.

7] Wiśniewski, A. [1995]. The Posing of Questions. Logical Foundations of Erotetic Inferences. Kluwer AP, Dordrecht.

\section{Background: fluid intelligence and deductive reasoning}

As fluid intelligence is the general ability to reason abstractly, identify patterns, and recognize relations, it is widely accepted that it correlates with fluency in deductive reasoning [4] in an abstract settings [6]. It is also widely accepted that fluid intelligence increases at least to some point in adolescence [1].

Some studies (e.g. [3]) suggest, that Gf can be improved by training. However, there are no clear indications as to the relation between Gf, deductive reasoning and longer-term educational experience.

\section{Background: erotetic reasoning}

In erotetic reasoning an iterrogative conclusion (question-conclusion) follows from premises: either only declarative, or both interrogative and declarative. Erotetic reasoning is a good representation of some techniques of problem solving:

1. by reduction of an initial problem to simpler ones,

2. by identifying missing information which is needed in order to solve the initial problem.

Validity of erotetic reasoning is grounded in erotetic counterparts of entailment. In the case of Inferential Erotetic Logic [7], which is the basis of the present study, such counterpart is erotetic implication.

\section{Results}

A one-way multivariate analysis of variance (MANOVA) was conducted to test group differences with respect to three dependent variables (APM, DR and ER test scores). There was a statistically significant difference between the groups on the combined dependent variables, $\mathrm{F}(6,202)=16.613, p<.001$; Pillai's Trace $=.661$; partial $\eta^{2}=.330$. Follow-up univariate ANOVAs showed that scores in all three tests were statistically significantly different between participants from all the three groups, using a Bonferroni adjusted $\alpha$ level of .017 (table 2). Games-Howell post-hoc analysis revealed that in both APM and DR there were significant differences between groups A and C as well as between groups B and C. In case of ER there were significant differences between all the three groups (table 3). A Spearman's rank-order correlation was run to assess the relationship between tests results (table 4). Interestingly, while in the whole group results in all the three tests significantly correlated with each other, correlations in groups $\mathrm{A}, \mathrm{B}$ and $\mathrm{C}$ followed different pattern. These results suggest that, although Gf and fluencies in both kinds of deductions are generally correlated, the scheme of these correlations is kind of complicated.

\begin{tabular}{cccccc}
$\begin{array}{c}\text { Table 1. Test scores statistics } \\
\text { Test } \\
\text { and group }\end{array}$ & $\begin{array}{c}\text { Difficulty } \\
\text { Index }\end{array}$ & Min & Max & Mean & SD \\
\hline \hline APM & $61,46 \%$ & 7 & 36 & 22.19 & 5.63 \\
A & $71,60 \%$ & 21 & 32 & 25.81 & 2.73 \\
B & $67,35 \%$ & 14 & 36 & 24.25 & 4.58 \\
C & $48,48 \%$ & 7 & 26 & 17.45 & 4.93 \\
\hline DR & $81,28 \%$ & 0 & 6 & 4.93 & 1.35 \\
A & $96,92 \%$ & 5 & 6 & 5.81 & 0.40 \\
B & $91,67 \%$ & 4 & 6 & 5.53 & 0.70 \\
C & $61,42 \%$ & 0 & 6 & 3.68 & 1.42 \\
\hline ER & $61,08 \%$ & 0 & 3 & 1.73 & 1.09 \\
A & $92,60 \%$ & 2 & 3 & 2.78 & 0.42 \\
B & $65,83 \%$ & 0 & 3 & 1.98 & 1.03 \\
C & $24,80 \%$ & 0 & 3 & .74 & 1.23 \\
\hline
\end{tabular}

Table 3. Games-Howell test results Test Mean

\begin{tabular}{cccc} 
and groups & increase & $95 \%$ CI & $p$ \\
\hline \hline APM & & & \\
A x B & 1.56 & {$[-.58,3.71]$} & .195 \\
A x C & 8.37 & {$[6.07,10.67]$} & .001 \\
B x C & 6.80 & {$[4.22,9.38]$} & .001 \\
\hline DR & & & \\
A x B & .29 & {$[-.03, .61]$} & .079 \\
A x C & 2.13 & {$[1.54,2.72]$} & .001 \\
B x C & 1.84 & {$[1.23,2.45]$} & .001 \\
\hline ER & & & \\
A x B & .80 & {$[.37,1.24]$} & .001 \\
A x C & 2.04 & {$[1.58,2.50]$} & .001 \\
B x C & 1.24 & {$[.67,1.80]$} & .001 \\
\hline
\end{tabular}

Table 2. Group differences

\begin{tabular}{lrrrr} 
Test & df & $F$ & $p$ & $\omega^{2}$ \\
\hline \hline APM & 2 & 36.809 & .001 & .405 \\
& 102 & & & \\
\hline DR & 2 & 49.948 & .001 & .482 \\
& 102 & & & \\
\hline ER & 2 & 40.750 & .001 & .431 \\
& 102 & & & \\
\hline
\end{tabular}

Table 4. Correlations $r_{S}$ between tests results

\begin{tabular}{lcccc} 
Tests & Overall & A & B & C \\
\hline \hline APM x DR & $.61^{* *}$ & .22 & .24 & .23 \\
\hline APM x ER & $.67^{* *}$ & .08 & $.42^{* *}$ & $.59^{* *}$ \\
\hline DR x ER & $.74^{* *}$ & $.43^{*}$ & $.55^{* *}$ & $.41^{*}$ \\
\hline${ }^{*} p<.05,{ }^{* *} p<.01$ & & &
\end{tabular}

\section{Summary and conclusions}

In this research we examined correlations between level of fluid intelligence (measured by Raven's Advanced Progressive Matrices test) and fluencies in two kinds of deductions: simple (operationalized by means of syllogistic reasoning tasks and measured by Deductive Reasoning test) and difficult ones (operationalized by means of erotetic reasoning and measured by Erotetic Reasoning test). Our subjects formed groups of lower (group C) and higher (groups A and B) abilities with respect to fluid intelligence and of extensive (group A) and very limited (groups B and $\mathrm{C}$ ) training in formal logic. We observed that, although groups A and B performed better than group C in all three tests, group A obtained significantly higher results than group B in tasks involving difficult deductions, while their performance in Raven's and Deductive Reasoning tests were comparable. Group C obtained lower results in all three tests. We conclude on this basis, somewhat at odds with CHC model of intelligence, that deductions of different complexities call for different abilities to be manifested and that fluency in difficult deductions, while related to fluid intelligence, depends also on subjects' experience and that this does not hold in case of simple deductions. 